\title{
Xerophthalmia in the Presence of Kwashiorkor
}

\author{
By H. A. P. C. OOMEN \\ Stella Maris Hospital, Macassar, Indonesia*
}

(Received 30 Fanuary 1954)

The patient with xerophthalmia is usually found in the polyclinic or during a more-orless superficial school or village inspection. He is a child, and as he comes from an environment unaccustomed to serious medical care, it it often difficult to make the parents understand the gravity of the condition and obtain their consent for his admission to hospital.

The patients with xerophthalmia described here presented also many signs of what is supposed to be protein malnutrition. Most were clear cases of kwashiorkor. As the aetiology of kwashiorkor is often believed to be confused by vitamin deficiencies, it would seem important to analyse the clinical picture as a whole. I regret that the regular estimation of serum protein and vitamin $A$ levels in the blood was impossible, but believe that clinical observation alone yielded some interesting facts, related with the aetiology of both xerophthalmia and kwashiorkor.

Because of the localization of signs and symptoms in the eyes and the easy success of specific therapy, treatment often tends to be restricted to relief of the eye signs, but if the patient can be nursed where he properly belongs, that is in hospital, it is not difficult to demonstrate that the eye lesions are part of a state of malnutrition. Hemeralopia in older children may be compatible with fair general nutrition, but xerosis conjunctivae, more commonly seen in infants and young children, is usually indicative of serious metabolic and nutritional disturbances.

METHODS AND RESULTS

\section{Description of subjects on admission to hospital}

This paper considers in some detail the clinical state of twenty-nine patients with xerophthalmia, observed in the children's ward of the Stella Maris Hospital at Macassar, Celebes. The children were all of Indonesian origin, the youngest 7 months and the the eldest 7 years old, the average age being 3 years, 2 months.

They were all ill and in need of admission to hospital for comprehensive investigation and care. They were not healthy children who suffered only from eye trouble, but their admission to hospital was not always achieved.

In only three of the twenty-nine patients was medical relief sought for the eye condition itself. The others visited the polyclinic for some other reason and the eye condition was then discovered. The reasons included cough, with or without fever (five cases), chronic diarrhoea, usually with fever (nine cases), emaciation and failure to grow (four cases), and generalized oedema (two cases).

* At present W.H.O. Medical Nutritionist, 69 Diponegoro, Djakarta, Indonesia. N ViII 3 


\section{Customary diet of Indonesian children}

No cases of xerophthalmia were seen in the Chinese children who occupied one-third of the beds in the children's ward. The customary nutritional practices may explain this difference. The Chinese in the community are generally well off, and their children as a rule get enough milk and protein. Before the war, however, xerophthalmia was observed fairly frequently in Chinese infants who were fed on 'condensed sweetened skimmed milk' (de Haas \& Meulemans, I938), but the milk did not appear to be on sale in the shops after the war. Breast-fed Indonesian children usually are in a fairly good nutritional state in the first 6 months of life. Thereafter, the staple food of most small children is rice. It takes a long time before the child is weaned completely, but the occasional sucking of the breast in the and and $3^{\text {rd }}$ years, although it may add a little protein to the diet, provides few calories.

In Macassar, as in many other towns of Indonesia, 'food' is to a considerable extent synonymous with rice. Maize and tubers form an unimportant part of the diet and rice is considered to be the food par excellence, in much the same way as milk is elsewhere. Children in the hospital ward are always content with rice and suspicious of other foods. Milk is virtually unknown to them, eggs evoke only slight interest, and considerable persuasion has to be used to get them to eat meat or fish. However, in their own homes, some greens including bajem (Amaranthus sp.) and kangkung (Ipomoea reptans), and some fruits-especially bananas, papaya and citrus fruits of various kinds-are consumed regularly.

Minor items of diet include sugar and rice flour cooked together, and sweet potato or banana, often cooked with a fresh emulsion of coconut oil. It is probable that as a group the children can get enough calories and that they consume reasonable amounts of vegetables and fruits, but that animal fat and protein are lacking in their diet. The food situation in Macassar is certainly not bad; buffalo or cow meat and sea-fish appear daily on most tables, and the families of the children under consideration could, in general, afford the average food.

It is regrettable that it was beyond our facilities to collect exact data on the previous diet of each child suffering from xerophthalmia, as this of course is of prime importance in understanding the disease. As far as I could judge from careful dietary histories, it appeared that the carotene content of the diet was satisfactory. The vitamin A content, however, was low, the amount of animal food consumed being small. There was a discrepancy between the estimated intake of carotene and the incidence of xerophthalmia. The discrepancy was noted also in a rural population in Atchin, Indonesia by Tijssen (1940) and in camp conditions in India by Aykroyd \& Krishnan (1936).

\section{Clinical observations in hospital}

\section{Weight and body development}

Vitamin A deficiency is usually thought to result in failure of growth and this criterion is in fact used in the biological assay of the vitamin in rat experiments. The criterion, however, is not specific, and the assay is fraught with large margins of error (cf. Gridgeman, 1945). 
Some difficulties were encountered in the assessment of the growth and weight deficits in the children.

There are no reliable figures for the average weights of normal Indonesian children of the race and geographical origin of our patients, but we may assume that the weights do not differ very much from those found in the population of Djakarta. Also, it is generally difficult to find out the age of our children accurately. For Fig. I, only those eighteen children whose reported ages could be verified, were chosen. Their weights are compared with the normal average for Djakarta children ('Tan Eng Dhong, Soekonto \& de Haas, 1939; Djoened Poesponegoro, 1952) and the average for

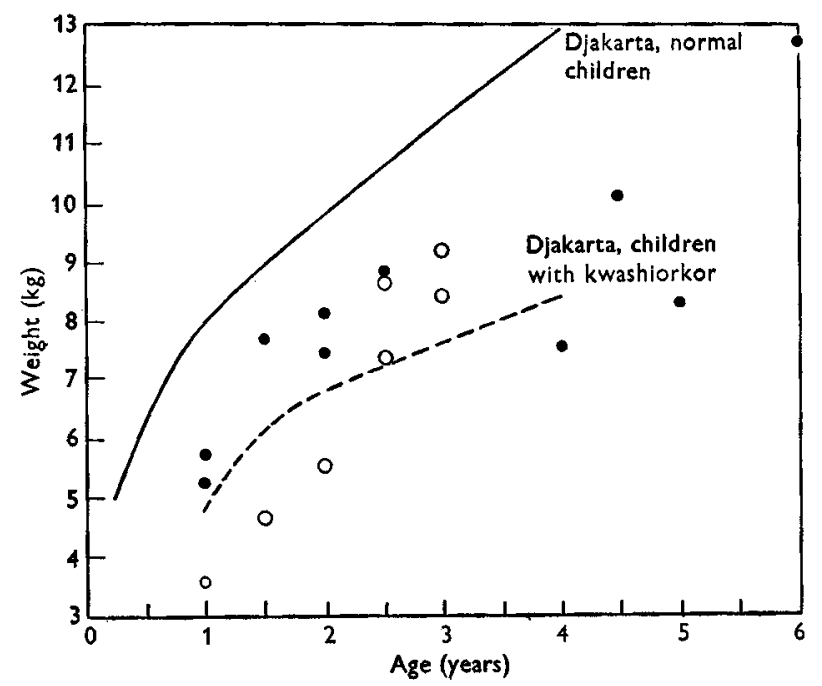

Fig. I. Weights of eighteen children with xerophthalmia at Stella Maris Hospital compared with average weights for normal children in Djakarta (Tan Eng Dhong, Soekonto and de Haas, I939; Djoened Poesponegoro, 1952) and of 125 children with kwashiorkor in Djakarta (Oomen, 1953). , children without oedema; $O$, children with oedema.

125 kwashiorkor cases in Djakarta (Oomen, 1953). A further difficulty in assessing weight was the presence of oedema, which was visible in seven out of the eighteen children; most of the rest were in a condition of marked hydrolability (see below). All the children were underweight, the deficit amounting in most instances to between 30 and $50 \%$ of the assumed normal weight. The large differences between individual cases were not closely related to the presence or absence of oedema. The children with the most serious eye affections were not those with the greatest weight losses.

The clinical appraisal of body development showed even more irregularity. Ten out of the eighteen children showed marked retardation, judged arbitrarily on a combination of weight, length and general development, three slight retardation, and five none. Asthenia was obvious, though difficult to express in grades. Some of the children were unable to sit upright, or supported their weight on their arms when they did so. Kyphosis when sitting and lordosis, with a big protruding belly when standing, were usual. Some of the children were unable to lift or hold up their heads. On palpation, muscle atrophy of a marked degree was nearly always found. The muscles were usually flabby, and in some instances seemed almost to have disappeared. 
Oedema was also an outstanding feature and was present in about half of the patients. The amount varied from a slight puffiness of the cheeks, or dorsum of hand or foot, to definite ascites and anasarca. Oedema was usually associated with muscular atrophy. In some children who were not oedematous on admission, hydrolability manifested itself in a late oedema occurring after the general condition had improved.

\section{Blood}

Anaemia was usually present to some degree but in only two cases was it severe. In thirteen patients the average haemoglobin was $10.8 \mathrm{~g} / 100 \mathrm{ml}$, and the average redcell count was $3,460,000 / \mathrm{mm}^{3}$ The blood showed no special microscopic characteristics.

\section{Urinary system}

The absence of abnormalities in the urinary system was interesting. It is known that vitamin A deficiency produces alterations in the epithelium of the urinary tract, and it has been said that the incidence of vesical calculus in small boys is often connected with the deficiency (Senduk, r949). In the twenty-nine xerophthalmia patients only two with minor symptoms of bladder irritation were encountered. On the other hand, none of the twenty-four young male patients operated on between 1949 and 1950 in the Stella Maris Hospital for vesical calculus showed eye or skin signs of vitamin A deficiency. van Stockum (1938) reported a similar lack of correlation from Java, and in 260 cases at Djakarta de Haas (193 I) found only one in which there was a possible relationship with vitamin A deficiency.

\section{Signs of vitamin A deficiency}

Eye lesions. Twenty-six of the twenty-nine patients showed signs of an active xerophthalmia. The bulbar conjunctiva looked dry, fatty, wrinkled and clay-coloured, especially in the medial and lower portions.

Bitôt's spots were considered to be a related but not a definite sign, as they may be visible for a long time after the cornea and conjunctiva have improved. Bitôt's spots and localized opacities were thought to be remnants of a previous deficiency state in three cases, notwithstanding the bad general condition of those cases at the time of examination.

Keratomalacia was present in a more or less severe form on the cornea of one or two eyes in fourteen patients. It was never found without xerosis.

Lack of lustre of the cornea, or shallowing of the anterior chamber was found in all cases. Six children had ulcers, or deep circular spots on the cornea; three were admitted with a perforation and another three developed a perforation or a serious herniation of the deep layers after admission. Of the twenty-five survivors, twentytwo left hospital with tolerably good vision in at least one eye. Panophthalmia caused the loss of three eyes.

Hemeralopia, too difficult to determine in the small children, was observed regularly in the older patients.

The routine therapy consisted of the normal hospital diet for small children, fortified with $5 \circ \mathrm{g}$ green gram and $5 \circ \mathrm{g}$ mashed liver daily (providing about $20 \mathrm{~g}$ extra 
protein). In emergencies single injections of 75,000 i.u. vitamin $A$ in oil and 100,000 units penicillin in oil were given daily. The ordinary treatment, however, was Io $\mathrm{ml}$. cod-liver oil given three times daily for 7 days, and this was usually successful.

Skin involvement. The skin was found to be intact and normal in eight of the twentynine children. Phrynoderma, a lesion sometimes thought to be specifically a sign of lack of vitamin $\mathbf{A}$ was found in only sixteen cases. In sixteen cases the skin was thin, dry, slightly coarse to the touch, or parchment-like, with loss of turgor. When skin so affected is improving, the outer, darker and keratinized layers become more obvious and peel off slowly, leaving a paler and softer new skin. Patchy or diffuse depigmentation, always a sign of serious malnutrition, occurred in ten patients. Sometimes it was noticeable only on the face, but in other instances it appeared more generalized, the child (without being exposed to sunlight) becoming darker-skinned as his general condition improved. Dry, atrophic and lighter, discoloured hair was noted in eight cases. Mosaic skin, fairly well marked, was present in one case. Crazy-pavement skin, one of the principal signs of kwashiorkor (Trowell, I949), was present in six children. There was marked hypertrophy of the lanugo covering-with lowering and spread of the temporal hair line on to the cheeks-in six patients aged respectively I, $2 \frac{1}{2}, 3,4,4 \frac{1}{2}$ and 6 years.

Respiratory system. All patients had an X-ray examination. Twenty-three showed more or less serious involvement of the respiratory system. In two, an acute disseminated bronchopneumonia with dyspnoea and fever was the outstanding feature; in another two, atelectasis-apparently tuberculous in origin-was found, and another showed a bronchitis that might have been tuberculous.

In seventeen other cases there was the appearance of a non-specific bronchitis, but no apparent general disturbance; in one case the Mantoux test was positive, but no definite diagnosis could be made.

Digestive system. On admission most of the children suffered from anorexia. Forced feeding was begun immediately in about half of the cases; in view of the nutritional state it was felt dangerous to delay this procedure which, in itself, encouraged the patients to eat less reluctantly.

The lips were thin, dry and fissured and the surface of the tongue appeared thin and glazed with flattened papillae. Redness and a more pronounced glossitis were noted in six cases, and fourteen showed atrophy of the oral mucosa. Eight of the children vomited frequently in the first few days after admission. When the stomach contents were being examined for tubercle bacilli, an absence or deficiency of hydrochloric acid was constantly found. Sixteen of the children had severe diarrhoea, probably due to bacillary dysentery. Often, when the dysenteric exudate had disappeared from the stools after therapy, the diarrhoea still persisted. In one case amoebic dysentery was definitely diagnosed.

In eight cases an intermittent steatorrhoea was noted, combined-in five cases-with dysenteric exudate. Short-lasting acholia was observed in two patients, but jaundice never.

Liver involvement. In the big, protruding, meteoristic belly which these children present, organs are often difficult to palpate, but in only six of the twenty-nine cases 
with eye signs was the liver not palpable. In twenty, it was definitely enlarged, in nine extending more than two fingerbreadths below the costal margin.

In twenty-two cases a liver biopsy was performed shortly after admission, and in ten it was repeated after about I month. A summary of the results is given in Table $I$. In ten instances there was a severe fatty infiltration so extensive that the liver cells

\section{Table I. Liver lesions* in twenty-two children with xerophthalmia,} as shown by serial biopsies

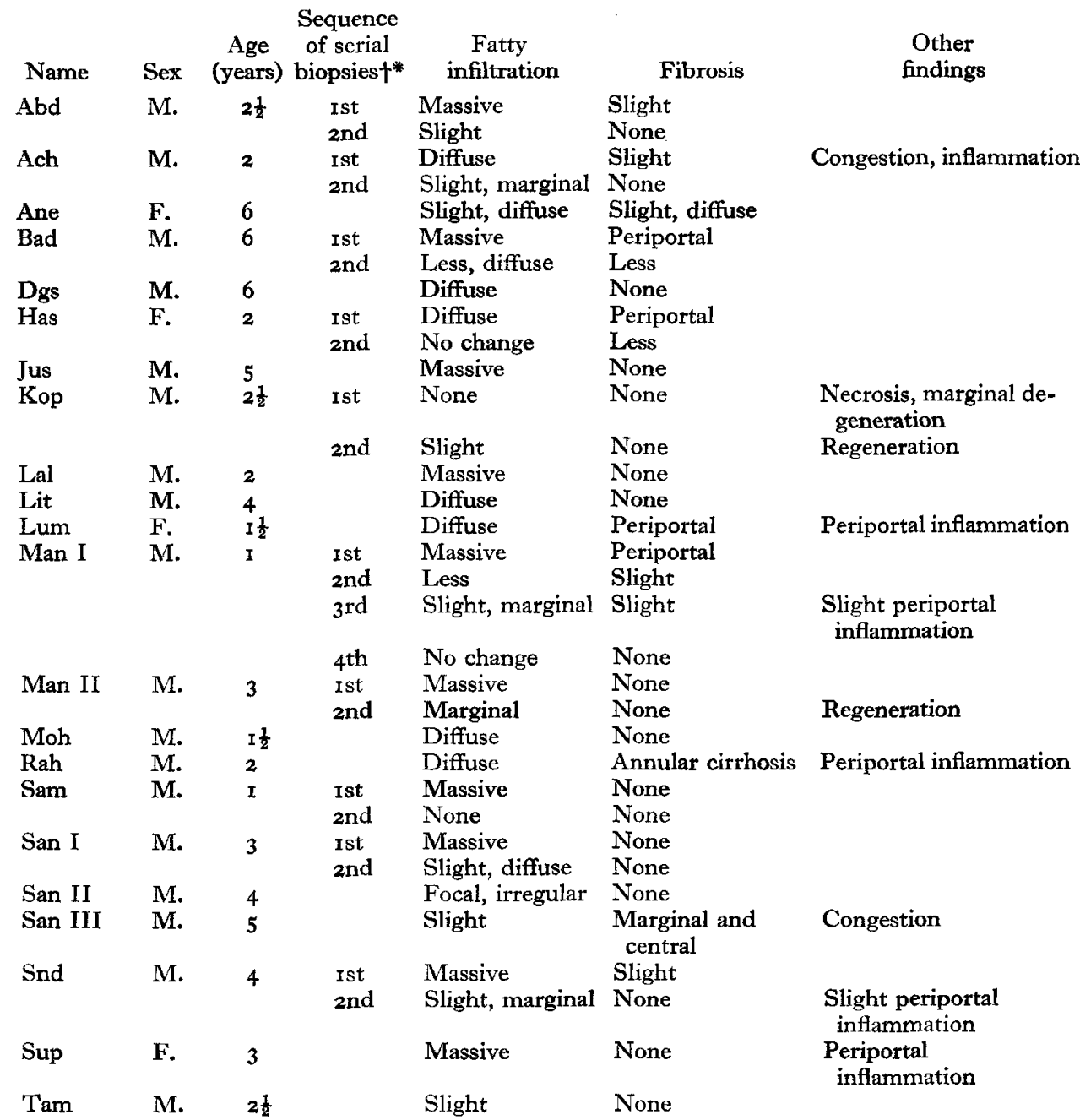

* The table summarizes the pathological diagnoses obtained from Dr Verdonk, Leyden, Professor Sutomo Tjokronegoro, Djakarta, and Dr Straub, Rotterdam.

$\uparrow$ The interval between biopsies was about I month.

could hardly be distinguished, the specimen differing from adipose tissue only in the contours of the portal tracts. The less-marked manifestations of steatosis were not especially noted, as they are commonly found in liver biopsies in our children. Different grades of fibrosis were observed. In nine cases there was a manifest fibrosis 
which, however, sometimes proved transitory; in one case there was a true juvenile cirrhosis. In these ten cases the fibrosis was accompanied by a varying degree of steatosis. Degeneration of the liver parenchyma, infiltration with round cells, and inflammatory congestion occurred here and there. The chief impression gained was that though the degree and type of the pathological lesion varied, none of the liver biopsies in the children with xerophthalmia showed a normal parenchyma.

\section{Interaction of infections}

The question whether specific agents might not be responsible for the pathological conditions described here must be considered.

Several of the patients suffered from one or more infectious diseases. Ascariasis was common, but ankylostomiasis and malaria were found only twice. Tuberculosis and dysentery seemed more important.

The influence of tuberculosis on the nutritional condition is well known, and could be observed daily in the children's ward. In studying the xerophthalmia patients a positive Mantoux test was found in four cases. This test is not entirely reliable; in a malnourished child with an atrophic skin, it may be negative at first and become positive when the general condition improves. In two cases there were several points worthy of note.

Rah. Male, age 2 years. Cachectic child; weight $7 \cdot 5 \mathrm{~kg}$. Heavy lanugo covering; dry thin hair with patchy baldness; severe xerosis corneae and conjunctivae; atrophic glossitis; severe muscular atrophy. Constant irregular extra systoles; moist râles over both lungs. X-ray examination: triangular area of infiltration of right middle lobe. Acid-fast bacilli in stomach contents. Right and left lobes of liver enlarged and palpable. Liver biopsy showed annular cirrhosis with proliferation of bile ducts and some inflammatory reaction and steatosis, but no tubercles. Stools diarrhoeic, with intermittent dysenteric exudate; Shigella (Type Y) isolated. Child died after 5 weeks. Diagnosis: Primary tuberculosis, malnutrition, liver cirrhosis, bacillary dysentery.

San III. Male, age 5 years. Emaciated, underdeveloped child; weight IO. I kg. Enlargement of cervical and inguinal lymph nodes. Xerophthalmia. X-ray examination (screening): hilar glands enlarged, interlobar pleuritis: spleen enlarged (Schüffner Scale III). Blood examination showed Plasmodium vivax on two occasions. Liver enlarged, edge three fingers below costal margin. Liver biopsy: congestion, marginal and central fibrosis of the lobules (incipient cirrhosis) but no tubercles. Diagnosis: disseminated tuberculosis, malnutrition, incipient liver cirrhosis, Vivax malaria.

Reviewing all the twenty-nine cases, a comment by Trowell (1949) comes to mind: 'The pattern produced is confused, but a certain drab monotony is seen in the clinical picture'. Here in the two cases described the monotony is broken, but in a familiar way. Both children suffered from florid tuberculosis, but one of them also had dysentery and the other malaria. Perhaps this sentence includes the three infections which have the most effect on nutrition. Could the infections also account for the fact that these children presented the most impressive fibrosis of the liver of all the cases examined? It might be concluded that the malnutrition here was probably of a secondary nature. When clinical malnutrition is being investigated, the dysenteries are frequently 
found. Here dysentery was present in about half the cases on admission, and in a few more cases it was found later. It may well happen that an acute attack of dysentery throws into imbalance a child whose state of nutrition is already labile, and has an even more profound effect on a child already malnourished. It is therefore difficult to decide whether the xerophthalmia in the cases of dysentery was of a primary or secondary character.

\section{Incidence of xerophthalmia in malnutrition}

In addition to the cases of malnutrition with xerophthalmia already described, another fifteen cases with malnutrition but without xerophthalmia were studied during the same period.

Table 2. Principal clinical signs, and results of liver biopsies for twenty-two children with malnutrition and xerophthalmia, compared with those for eleven children with malnutrition but without xerophthalmia

\begin{tabular}{|c|c|c|c|c|c|c|c|c|c|}
\hline Name & Sex & $\begin{array}{c}\text { Age } \\
\text { (years) }\end{array}$ & $\begin{array}{l}\text { Crazy } \\
\text { pavement } \\
\text { skin }\end{array}$ & $\begin{array}{l}\text { Respiratory } \\
\text { signs }\end{array}$ & $\begin{array}{c}\text { Digestive } \\
\text { upset }\end{array}$ & $\begin{array}{l}\text { Muscular } \\
\text { atrophy }\end{array}$ & Oedema & $\overbrace{\text { Steatosis }}^{\begin{array}{r}\text { Resu } \\
\text { liver } \mathrm{b}\end{array}}$ & $\underbrace{\begin{array}{l}\text { lts of } \\
\text { jiopsy }\end{array}}_{\text {Fibrosis }}$ \\
\hline \multicolumn{10}{|c|}{ Twenty-two cases with xerophthalmia } \\
\hline Abd & M. & $2 \frac{1}{2}$ & + & + & + & + & ++ & ++ & + \\
\hline Ach & M. & 2 & & + & + & + & & + & + \\
\hline Ane & F. & 6 & & & + & & + & + & + \\
\hline $\mathrm{Bad}$ & M. & 6 & & + & + & + & & ++ & + \\
\hline $\mathrm{Dgs}$ & M. & 6 & + & + & + & + & + & + & \\
\hline Has & F. & 2 & & + & & & & + & + \\
\hline Jus & M. & 5 & + & & + & + & + & ++ & \\
\hline Kop & M. & $2 \frac{1}{2}$ & & + & + & + & & & * \\
\hline Lal & M. & 2 & & + & + & + & + & ++ & \\
\hline Lum & F. & I $\frac{1}{2}$ & & + & + & + & + & + & + \\
\hline Man I & M. & $\mathbf{I}$ & & + & + & & + & ++ & + \\
\hline Man II & M. & 3 & + & + & + & + & + & ++ & \\
\hline Min & F. & $4 \frac{1}{2}$ & & & & + & + & & + \\
\hline Moh & M. & $\mathbf{I} \frac{1}{2}$ & & & + & + & & + & \\
\hline Rah & M. & 2 & & + & + & + & & + & ++ \\
\hline Sam & M. & I & & + & & + & & ++ & \\
\hline San I & M. & 3 & & + & + & + & + & ++ & \\
\hline San II & M. & 4 & & & + & + & & + & \\
\hline San III & M. & 5 & & + & & & & + & ++ \\
\hline Snd & M. & 4 & + & + & + & + & ++ & ++ & + \\
\hline Sup & M. & 3 & + & & + & & + & $+t$ & \\
\hline Tam & M. & $2 \frac{1}{2}$ & & + & + & & & + & \\
\hline Total & & & 6 & I6 & 18 & I6 & 12 & 20 & I I \\
\hline \multicolumn{10}{|c|}{ Eleven cases without xerophthalmia } \\
\hline Abd & M. & $\mathrm{I} \frac{1}{2}$ & + & + & + & & + & $+t$ & \\
\hline Ami & M. & $\frac{1}{2}$ & & & + & & & ++ & \\
\hline Bat I & M. & $\mathrm{r} \frac{1}{2}$ & + & + & + & + & + & + & + \\
\hline Bat II & M. & $\frac{\pi}{2}$ & & & + & + & + & + & + \\
\hline Haw & F. & 3 & + & & + & + & + & + & + \\
\hline Meg & M. & $I \frac{1}{2}$ & & & + & + & + & ++ & + \\
\hline Mun & M. & 4 & + & + & + & ++ & ++ & ++ & \\
\hline Rap & F. & 2 & + & + & & + & & + & $t$ \\
\hline Rom & M. & $2 \frac{1}{2}$ & & + & + & + & + & + & \\
\hline $\mathrm{Sai}$ & $\mathrm{M}$ & 2 & & & + & + & + & ++ & \\
\hline Sar & M. & $2 \frac{1}{2}$ & + & + & + & + & + & ++ & \\
\hline \multirow[t]{2}{*}{ Total } & & & 6 & 6 & 10 & 9 & 9 & I I & 4 \\
\hline & & & ecrosis. & & & Tube & & & \\
\hline
\end{tabular}


In eleven of these a liver biopsy was performed. A summary of the biopsy findings, together with the principal clinical signs, is compared in Table 2, with the findings in the cases of xerophthalmia in which liver biopsy was also performed.

Because of the limitations of the material and means of investigation at our disposal, it was impossible to compare the two groups exactly, but certain general principles emerged.

As to disturbances in general condition, there seemed to be little difference between the cases with xerophthalmia and those without. Using the definition of Brock \& Autret (1952), twenty-two of the cases of xerophthalmia, and six of the other cases of malnutrition, could be diagnosed as kwashiorkor. In the other cases the kwashiorkor picture was not developed fully, but still the patients showed a close relation to the kwashiorkor syndrome.

The most important fact brought out by the review of these young Indonesian patients seems to be that, contrary to the conception of xerophthalmia still frequently held, the condition does not represent the clinical entity of a single avitaminosis but rather indicates an ominous type of general malnutrition. Treatment of the eye condition only, or consideration of a specific vitamin deficiency, is not enough.

\section{DISCUSSION}

Usually when the child is first seen, the danger of blindness is very near. Fortunately, specific treatment is easy and gratifying. As a rule xerophthalmia reacts promptly to cod-liver oil, even in children who are doomed. However, a cure with the eye condition as its exclusive aim, implies a vain effort (van Stockum, 1938). After the danger of perforation and panophthalmia has been averted, there remains the more difficult problem of the general malnutrition. Four of the twenty-nine patients died after the eye condition had improved and two more left hospital in a hopeless state. Six of the fourteen other cases of malnutrition without xerophthalmia also died.

It appears that the eye condition behaves as an individual clinical entity on the one hand, and also as an accompaniment of general malnutrition. It must be stressed that these children were in a period when growth is normally very active and that the growing organism behaves differently from the adult in many ways. Our observations are not therefore comparable with those of Nicol (r949) who describes (generally) minor malnutrition and signs of avitaminosis $\mathrm{A}$ in a Nigerian peasant population, except in so far that in his material also, there was a striking correlation between eye and liver disorders.

In Indonesia the vitamin A content of the blood serum has often been examined as a routine procedure during food surveys. Data from the Pulusari district in central Java, where maize is the main food and seasonal famine during harvest failure is common, are given by van Veen \& Lanzing (1940) and are of interest with reference to this discussion. During the seasonal famine period, nutritional oedema is fairly frequent. No correlation was found in adults or children between the vitamin A content of the blood and the incidence of the oedema. Less than $50 \mathrm{i} . \mathrm{u}$. vitamin A/100 ml. serum were found in twelve of sixteen children (5-10 years old) with oedema, 
and in six of eleven cases (2-5 years old) without oedema. In other cases values from IOO to 150 i.u. were found. Clinically recognizable vitamin A deficiency was not observed. There was lack of correlation between malnutrition and vitamin A blood levels just as, in our cases, there was lack of correlation between malnutrition and xerophthalmia.

In the rural surveys of van Veen \& Postmus (1947) in Java, xerophthalmia seemed always linked to a protein-deficient diet, at least in small children. Referring to xerophthalmia cases discovered during a survey in Segalaherang they wrote: 'Most of the (68) children (2-8 years of age), were in poor physical condition, and many did not tolerate cod-liver oil treatment well because of intestinal disease. 24 died within a short period.... Although adult requirements were more than met, the children received far too little (protein).'

Xerophthalmia appears to be an important characteristic of the types of malnutrition present everywhere in Indonesia (de Haas, Posthuma \& Meulemans, 1940; Oomen, I95 I, I953); the significance of vitamin A as involved in the cause and cure has long been recognized there (Wille, 192I; de Haas, 193I). As a public health problem however, it was generally estimated only on the basis of vitamin A or carotene consumption, and managed on that basis.

Several authors have stressed the relation between the impaired nutritional state and the eye signs. Straub (1927) searched for a connexion between 'anhydraemia' and the 'exsiccation' of the cornea which he observed in coolie infants on estates in Sumatra. van Stockum (1938) strongly advocated the importance of 'good nutrition' apart from specific therapy. But generally, though xerophthalmia and keratomalacia were well known to doctors in Indonesia, the broader background of malnutrition was not fully appreciated or recorded. It was not until 1940 that de Haas et al. (1940) showed, on the evidence of 123 cases from the central hospital in Djakarta, that 'dystrophy' (general malnutrition) was present in $74 \%$, helminthiasis in $14 \%$, bronchopneumonia in $28 \%$ nutritional oedema in $24 \%$, dysentery in $15 \%$, enteritisdyspepsia in $7 \%$ and pyuria in $5 \%$. They said that dystrophy and xerophthalmia in these children were going hand in hand, while the vicious circle was being closed by the various infections.

The cases analysed here can be taken as representative of the average picture of xerophthalmia in the town of Macassar, an urban community on the coast of a region where there is a surplus of rice and malaria is not very prevalent. With different environmental backgrounds the problem may present different features. Here the xerophthalmia appears simultaneously with general malnutrition, and the question whether it is primary or secondary in aetiology is difficult to answer. Viewed from the aspect of the probably very low vitamin A intake, it might be called primary, and secondary when viewed as due to faulty utilization of the carotene present in the diet. The serious lesions of the liver, and the disturbances of intestinal functions, might incline one to regard it as a consequence of defective protein ingestion, absorption or metabolism.

We can only state the complexities and difficulties which puzzle the clinician as well as the public-health worker. Why is xerophthalmia associated with 'malignant 
malnutrition'? What is the relation between the vitamin A deficiency that predisposes to the former, and the lack of adequate protein that influences the latter? Why do we find an injured liver so constantly? Why does xerophthalmia appear in some cases of malnutrition and not in others? Why do we hear so little about the condition from other countries where kwashiorkor is considered a widespread problem? The word xerophthalmia is not mentioned in the Brock \& Autret (1952) report on kwashiorkor in Africa. When it occurs as a problem in rice-eating countries, where is the linkage with rice? Why is cod-liver oil by mouth such a rapid and efficient remedy in spite of the abnormal state of the liver and intestines? Why does the consumption of vegetables and fruit, containing ample carotene, appear to have such a small influence on prevention?

The observations here reported are from the clinical angle only. This approach has been deliberate, because laboratory diagnosis has little bearing on the recognition of the condition, especially in Indonesia where so many of the cases are only seen in the course of general medical practice. A major public-health problem exists, of which the individual is the core-the small uncomfortable child-unable to express himself properly-often more handicapped by the ignorance than by the poverty of his parents, threatened with blindness and desperately weakened by a frustrated metabolism. It is this individual who deserves consideration from every point of view and not merely from the aspect of the lack of a single vitamin. The concentration on that one aspect has too often been the fault of the clinical text-books.

\section{SUMMARY}

I. Of forty-four Indonesian children between the ages of 7 months and 7 years, with manifestations of advanced malnutrition, twenty-nine presented xerophthalmia and keratomalacia, mostly to a serious degree. The latter conditions were studied with special reference to background and clinical signs.

2. As the children came from an environment where the general food situation was not bad, it appeared that the incidence of deficiencies was due to parental ignorance rather than poverty. Carotene intake appeared satisfactory, but the intakes of animal protein and vitamin $A$ were very low.

3. In a few cases xerophthalmia proved to be compatible with slight weight loss and normal growth, but in more than half the cases weight reduction and growth retardation were severe.

4. In twenty-two cases of xerophthalmia liver biopsy was performed with the following findings: massive fatty infiltration, ten; diffuse or marginal fatty infiltration, eleven; fibrosis, nine. Enlargement of the liver was present in most cases.

5. The eye affection was the reason for seeking medical advice in only three of the twenty-nine cases. The frequency of other clinical findings is described; they included oedema and lesions of the skin, respiratory infections and dysentery. Two cases of tuberculosis presented the most severe liver fibrosis. The infections made it difficult to decide whether the general condition was essentially nutritional in origin, or whether malnutrition was secondary.

6. Xerophthalmia is a major complication of kwashiorkor and allied conditions in 
Indonesia. Interest, curative as well as preventive, should be devoted to the whole clinical picture and not to the eyes alone. None of the cases in this series appeared to show an isolated primary vitamin A deficiency.

The author wishes to express his gratitude to Dr Verdonk, Leyden, Professor Sutomo Tjokronegoro, Djakarta, and Dr Straub, Rotterdam, for their kind and patient co-operation.

\section{REFERENCES}

Aykroyd, W. R. \& Krishnan, B. G. (1936). Indian F. med. Res. 23, 741.

Brock, J. F. \& Autret, M. (1952). Bull. World Hlth Org. 5, I.

de Haas, J. H. (1931). Meded. Dienst Volksgezondh. Ned.-Ind. 26, 48.

de Haas, J. H. \& Meulemans, O. (I938). Lancet, 234, I т Iо.

de Haas, J. H., Posthuma, J. H. \& Meulemans, O. (1940). Geneesk. Tijdschr. Ned.-Ind. 80, 928.

Djoened Poesponegoro (1952). In Kanaka dibawah umur 6 tahum. [Kementerian Kesehatan, editor.] Djakarta: Health Ministry.

Gridgeman, M. F. (I945). The Estimation of Vitamin A, and ed. Port Sunlight, Cheshire: Lever Brothers and Unilever Ltd.

Nicol, B. M. (1949). Brit. F. Nutr. 3, 25.

Oomen, H. A. P. C. (1951). Docum. neerl. indones. Morb. trop. 3, 49.

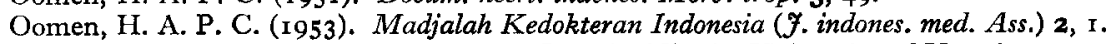

Senduk, R. C. L. (1949). Urinestenen te Batavia. Thesis, University of Utrecht.

Straub, M. (I 927 ). Kindersterfte ter Oostkust van Sumatra. Thesis, University of Amsterdam.

Tan Eng Dhong, Soekonto, R. \& de Haas, J. H. (1939). Indian F. Pediat. 6, I63.

Tijssen, J. ( I940). Voeding, 2, 45 .

Trowell, H. C. (1949). Trans. R. Soc. trop. Med. Hyg. 42, 417.

van Stockum, M. J. (1938). Geneesk. Tijdschr. Ned.-Ind. 78, 856 .

van Veen, A. G. \& Lanzing, J. C. (1940). Geneesk. Tijdschr. Ned.-Ind. 80, 5 I4.

van Veen, A. G. \& Postmus, S. (1947). F. Amer. diet. Ass. 23, 669.

Wille, F. (1921). Trans. 4th Congr. Far Eastern Ass. trop. Med. 1, 245. 